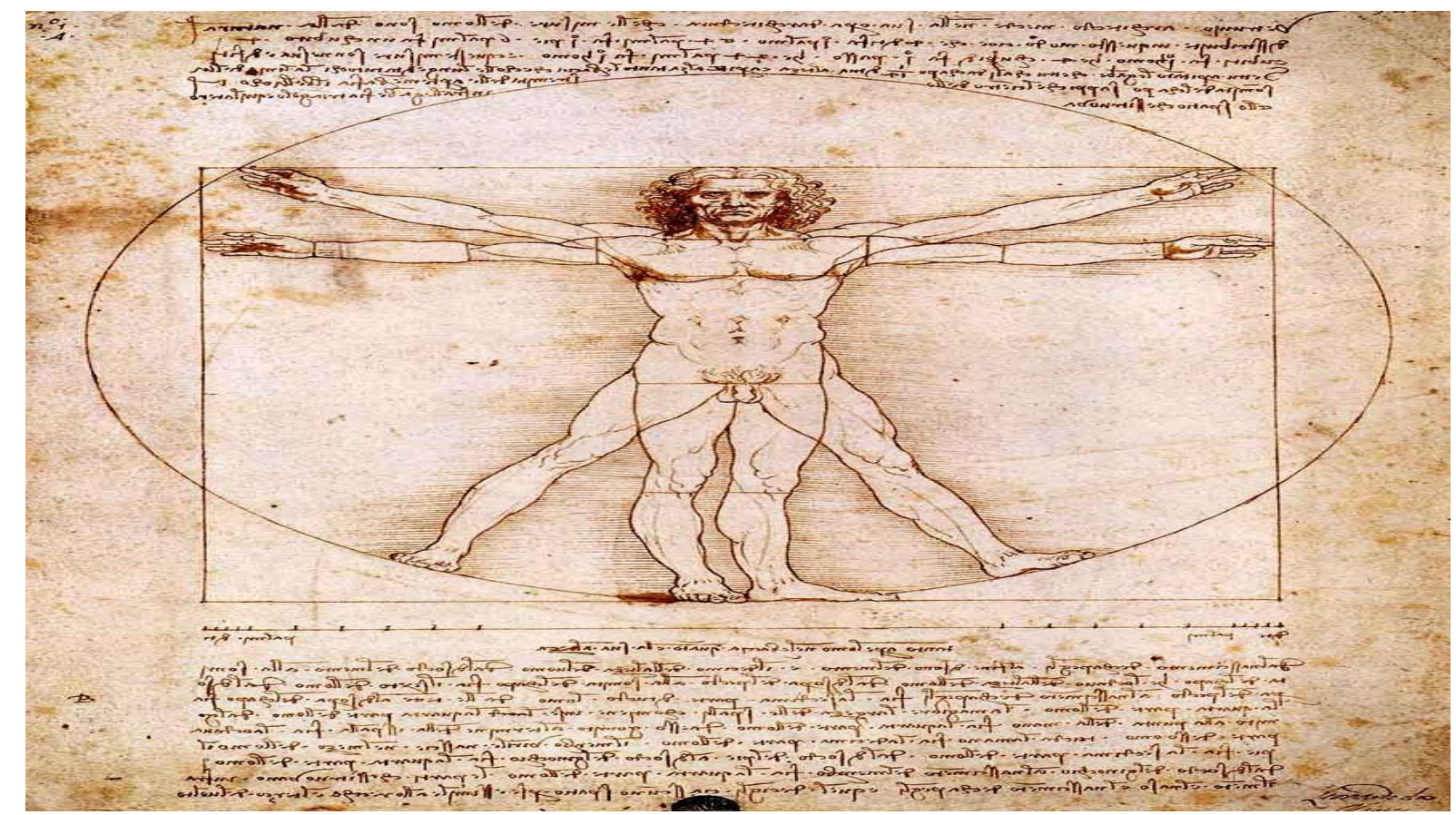

Fonte de imagem : Saher Cultural

Pintura : Leonardo da Vinci

\title{
Desenvoltura no estudo de Anatomia Humana Prática.
}

Resourcefulness in the study of Human Anatomy Practice.

Autor : Jorge Eduardo Cortz Sernaglia/Estudante de Ed.Física

Vínculo Institucional : Unimetrocamp/Wyden-Campinas/SP

Artigo Científico : 10/07/2019

\section{Resumo :}

Atualmente,a maioria dos estudantes se deparam com a dificuldade na aprendizagem da prática de Anatomia Humana,é onde começam a recorrer a meios mais práticos de Estudo dessa Matéria.Entretanto,muitos estudantes não sabem o ponto de partida para que a Anatomia prática ande de "mãos dadas" com a Anatomia teórica .

\section{Abstract :}

Currently, most students are faced with the difficulty in learning the practice of Human Anatomy, where they begin to resort to more practical means of Study of this 
Matter. However, many students do not know the starting point for practical Anatomy walk "Hand in hand" with theoretical anatomy.

Palavras-chave : Anatomia,Praticidade,Prática,Estudantes. key-words : Anatomy,Practicality,Practice,Students.

\section{Introdução :}

A Anatomia Humana é uma Matéria muito complexa,seja na parte teórica ou na parte prática dela.O ensino dessa disciplina vem sendo cada vez mais vista como um desafio para os alunos que estão cursando a área de saúde,pelo simples fato de ser uma matéria extensa e complexa para muitos!

Algumas alternativas com o intuito de ajudar na aprendizagem dessa disciplina foram tomadas.

A proposta desse projeto foi pensar em uma maneira de facilitar e entreter $\mathrm{o}$ aluno, de um modo que ele realmente conseguisse raciocinar e ter total compreensão na parte teórica da disciplina,para que assim,ele compreenda a Anatomia Humana como um todo. Um modelo de aprendizagem foi apresentada para uma minoria de alunos(aos quais apresentavam dificuldade de entendimento na matéria prática,devido a motivos pessoais de não se sentirem confortáveis ao mexer em cadáveres no laboratório),onde o projetor processou imagens de Músculos da região da cabeça.Um marcador de texto foi utilizado para poder escrever a nomenclatura dos músculos nos seus devidos lugares encima do holograma emitido pelo projetor.Os alunos tiveram um tempo máximo de 15 minutos para estudar os músculos da região (abrindo alguns minutos à mais por exceções).Os mesmos fizeram perguntas e questionamentos referentes aos músculos da região citada,e resolveram fazer comentários entre eles nos minutos restantes.

\section{Material e métodos :}


Uma grande porcentagem dessa Avaliação dependeu do local em que decidimos fazê-la.Pois precisávamos de uma sala com um projetor disponível,cujo qual seria utilizado para obter um holograma da parte do corpo estudada.Durante a iniciação da elaboração desse método de estudos,surgiram questionamentos de como seria a procedência para a memorização da parte prática da Anatomia Humana.Foi o momento em que entramos em um consenso de que não necessariamente se tratava de uma memorização,mas sim, de uma compreensão do tema que estava sendo abordado.Alguns minutos após o projetor ser ligado,surgiram as dúvidas de como seria o processo de aprendizagem durante a explicação ...

chegamos a conclusão que : se a explicação de cada músculo da região da cabeça fosse explicada detalhadamente e em seguida a nomenclatura deles fossem escritas com um marca texto encima,seria bem mais fácil a compreensão.Depois da explicação detalhada de cada músculo e o nome científico de cada um deles,exatamente 15 minutos foram dados para que os alunos estudassem por conta própria,ocasionando em uma roda de interação entre eles para esclarecerem o por quê da resposta individual de cada um!Logo após o término do tempo,pediram que disponibilizasse apenas mais 10 minutos,o que consequentemente resultou em mais interação entre eles.Cada aluno resolveu expressar o raciocínio que o levou a chegar a determinada conclusão : foi utilizado um apagador para que as explicações anteriores fossem apagadas,um marca texto foi dado a cada um deles para que assim,conseguissem escrever encima do holograma refletido pelo projetor,cada nomenclatura de cada músculo discutido e estudado antes e depois dos minutos propostos e acrescentados nesse modelo de aprendizagem.

Resultaram num total em média de 30 minutos do processo proposto para a compreensão da Anatomia Prática.O lugar mais apropriado para que se possa estudar a Anatomia de forma prática,é em um laboratório de anatomia ... mas,por motivos de desconforto e motivos pessoais de cada aluno devido ao ambiente,algumas medidas tiveram que ser tomadas, onde ocorreram adaptações a essa quantia mínima de alunos.Ou seja “...em tudo,sempre serão desconfortáveis as mudanças;todavia, devemos nos moldar,rapidamente,às adaptAÇÕES." (KABRAL ARAUJO).

\section{Resultado :}

Depois de horas de empenho nos estudos,os alunos decidiram tirar uma foto da lousa,onde os mesmos haviam exercitado a reflexão proposta,para que assim,pudessem estudar ainda mais a qualquer momento!Uma semana antes das 
provas de anatomia (teórica e prática) decidiram se encontrar novamente,onde cada um relatou mais facilidade na aprendizagem da Anatomia prática como um todo.Nomenclaturas de músculos que ambos estavam com dificuldade de compreender,imediatamente na hora da interação com o grupo foram não só compreendidas,como também entendidas.Fazendo com que automaticamente a Anatomia humana geral fosse compreendida na prática e teoricamente!Ao decorrer da semana,o nervosismo de antes,que acontecia pelo fato das provas da disciplina,foram ficando para trás... Inclusive relataram estar mais ansiosos para realizar a prova,para que assim,pudessem desempenhar horas e horas de estudos realizados, na prova que estava por vir.

Então,o dia tão esperado chegou,com certeza muito mais preparados psicologicamente do que antes,com mais confiança neles mesmos e com mais estudo.Primeiro houve a prova teórica,logo depois,alguns minutos foram dados para todos se prepararem para prova prática.Todo processo da avaliação foi explicado nos mínimos detalhes para todos alunos antes da prova.Depois do término da prova (Prática),nos encontramos em frente ao laboratório de Anatomia,para que então pudessem se expressar e dizer o pressentimento de cada um... No momento da conversa,notou-se de cada aluno,mais confiança neles mesmos. Um tempo depois,a nota foi postada,o que aconteceu?Todos ficaram desesperados para abrirem o site e verem suas notas. No desfeche de tudo,todos tiraram notas excelentes, perguntaram entre si a nota de cada um,felizes com o resultado,mencionaram que,o que de fato os ajudou foi o método de ensino utilizado,ajudando tanto na parte prática quanto na parte teórica,entendendo o real motivo da compreensão,e não somente decorar a matéria,como eles mesmos achavam que iria ser o procedimento!Como dizia (Ésquilo) "a disciplina é a mãe do sucesso".

\section{Discussão :}

No primeiro momento do planejamento de estudo prático da Anatomia Humana,foram questionados pelos próprios alunos se esse método ajudaria tanto no entendimento da aula prática,quanto da teórica. Explicações foram feitas de acordo com cada questionamento pontuado de cada aluno.Uma das principais perguntas feitas por eles,foram:como esse método ajudaria a agregar conhecimento prático,se a maneira de ensinar é teórica ? Pois a resposta foi simples : A maneira a ser ensinada,em partes,seria realmente teórica,porém a mesma metodologia serviria para ser usada no momento prático das aulas! Como ? Usando a reflexão utilizada na aprendizagem teória,só que por sua vez usá-la na prática.Concluindo-se 
que,alguns dos principais aspectos positivos utilizados nesse modelo é que eles realmente facilitam a aula prática.Sem a utilização de laboratórios e equipamentos sofisticados.

Silva e Guimarães (2004) consideram que "ensinar significa resgatar no aprendiz uma integração do racional com o estético, conjunto da razão e do sonho no qual conhecer algo novo é maravilhar-se, trabalhar duro, esforçar-se e descobrir". Sempre buscando uma alternativa para que o aluno tenha $100 \%$ de aproveitamento.O projeto foi desenvolvido e colocado em prática pelo autor do artigo,procurando ajudar os alunos do mesmo e de outros cursos de saúde,experimentando novas maneiras de agregar mais conhecimento prático da disciplina e procurando sempre novas formas de aprender anatomia durante sua jornada acadêmica,não servindo apenas para o aprendizado de Anatomia Humana,mas que também seja um estímulo para que o próximo use sua criatividade para que consiga desenvolver novas formas de aprendizagem,independentemente da área de atuação na sua graduação .

\section{Conclusões :}

O objetivo do método relatado,foi com sucesso atingido,teve um resultado condizente com o que foi proposto para essa quantia mínima de alunos.A base de tudo para que o método realmente funcionasse, foi ter realizado tudo isso em uma sala que continha um projetor,para que assim,o processo de fato pudesse ser realizado e ajudar os alunos. O segundo passo,que foi o essencial para que tudo desse certo,foi o desempenho dos alunos que se propuseram a realizar esse novo método proposto para eles.Um fato importante que houve em todo processo,que não pôde passar despercebido,foram as perguntas de cada um deles,questionaram o por quê de cada passo realizado na aprendizagem ... O questionamento não pode nunca ser deixado de lado,pode não parecer para muitos,mas mínimos detalhes fazem muita diferença,ainda mais quando se trata de Anatomia Humana.O máximo de informações foram passadas detalhadamente,mostrando formas de exemplificação para cada ensinamento,o que fez toda a diferença,já que cada um entende de uma maneira diferente ... (Todos nós aprendemos de uma maneira diferente do que a dos outros).Pois não existe apenas um entendimento de métodos práticos e teóricos. Essa maneira de estudo abriu um novo caminho para que futuros estudantes,não só da área de saúde,como de outros cursos,consigam abrir caminhos para novas descobertas de estudo.Pois os métodos de estudos,em qualquer disciplina de qualquer curso,são ilimitados!"O limite só vai chegar,no momento em que pararmos de pensar"(Cortz Jorge).Por último, mas não menos importante,foi a confiança de cada um,essa é a parte em que se dá a estrutura 
desde o início até o final dessa experiência."Confiar em si mesmo,como isso é importante e faz diferença na vida,confie cada passo que você da,confie cada palavra que você diz,confie no seu sorriso"(Rafael Silveira). Toda dedicação valeu a pena,não só na elaboração desse método,como também na dedicação dos alunos que se propuseram a executá-lo.Aproveitar sempre o máximo de informações enquanto pode,é essencial,até mesmo porque quando juntamos elas,um novo entendimento pode ser formado.Em relação a Anatomia em si,por vezes muito complexa,se percebe ainda mais a importância da aula teórica andar lado a lado com a aula prática.Se não estiverem sendo entendidas por completo, provavelmente na hora do estudo haverão muitas dúvidas, havendo mais um motivo para serem compreendidas amplamente.Expressar-se é essencial,principalmente quando temos dúvidas a serem apresentadas.

\section{Citações :}

“...em tudo,sempre serão desconfortáveis as mudanças;todavia, devemos nos moldar,rapidamente,às adaptAÇÕES." (KABRAL ARAUJO).

"ensinar significa resgatar no aprendiz uma integração do racional com o estético, conjunto da razão e do sonho no qual conhecer algo novo é maravilhar-se, trabalhar duro, esforçar-se e descobrir". (SILVA e GUIMARÃES)

(Ésquilo) "a disciplina é a mãe do sucesso".

“O limite só vai chegar,no momento em que pararmos de pensar"(Cortz Jorge)

"Confiar em si mesmo,como isso é importante e faz diferença na vida,confie cada passo que você da,confie cada palavra que você diz,confie no seu sorriso"(Rafael Silveira).

\section{Referências :}


SALING, S. C. Modelos didáticos: uma alternativa para o estudo de anatomia. Paraná, 2007. Disponível em:

<http://cacphp.unioeste.br/eventos/OLD_mesmo_antigos/.../EE_08.pdf> Acessado em: 28, abril, 2012.

SILVA, R.A da; GUIMARÃES, M. M. Arte educação: facilitando o ensino de morfologia. Educere. Umuarama. V.4, n.1, p.55-63, 2004.

ORLANDO, T.C. Planejamento, montagem e aplicação de modelos didáticos para abordagem de biologia celular e molecular no ensino médio por graduandos de ciências biológicas. Revista Brasileira de Ensino de Bioquímica e Biologia Molecular, Minas Gerais, v.1, n.1, p1-17, 2009.

CAMPUS NETO, F.H.C.; MAIA, N.M.F. e S.; GUERRA, E.M.D. A experiência de ensino da anatomia humana baseada na clínica. Fortaleza: Universidade Metropolitana de fortaleza, Anais do XXIII Congresso Brasileiro de Anatomia, 2008.

FORNAZIERO C.C,GIL C.R.G : Novas tecnologias aplicadas ao ensino da anatomia Humana. Paraná : Londrina v .27, $n^{\circ}$ 2, maio/ago. 2003

SOUSA JÚNIOR, I; CARVALHO; [et al 2010]. Métodos de ensino aprendizagem em anatomia humana. In: $\mathrm{V}$ Congresso de Pesquisa e Inovação da Rede Norte e Nordeste de Educação Tecnológica. Maceió - AL 2010.

CAMPOS, L. M. L.; FELICIO, A. K. C.; BORTOLOTO, T. M. A Produção de jogos didáticos para ensino de ciências e biologia: uma proposta para favorecer a aprendizagem. Disponível em: <http://www.br/ prograd/PDFNE2002/aproduçãodejogos. Pdf> Acesso em: 15 Jun. 2011.

ALMEIDA, P. L. Educação lúdica: técnicas e jogos pedagógicos. $5^{\circ}$ ed. São Paulo: Loyola, 1998. 